\title{
An Eco-Leap Forward: Shifting Agriculture
}

\author{
Xinyu Xiao, Hai Anh Nguyen
}

ABSTRACT - Human activity has been changing the surface of the earth for several thousand years. In recent decades, the rate of change however was accelerated in the Yangtze River Delta, propelled by China's rapid and continually chaotic process of urbanization and industrialization. How can our cities eventually face haze, water pollution, soil contamination, and natural disasters caused by climate change? The challenge is indeed to explore how to achieve an ecological resilience by enhancing biodiversity and by reviving and revising productive landscape.

Keywords: biodiversity, productive landscape, resilience, Yangtze River Delta

The concept of "resilience," which helps to describe system responses to change, has been increasingly attracted more and more attention. Within that term, biodiversity is often thought to be a key feature, underpinning the resilience of ecosystems (Mori, 2016). Nonetheless, current species loss considerably affects ecosystem function. Thus, nature in cities, and biodiversity in particular, may need to be employed to address these unprecedented challenges (Ahern, 2016), and could play an essential role in providing the ecosystem services that every city relies on to be sustainable and resilient. Very much linked to that is the story of the countryside. The development of the agricultural sector is among the most efficient implements to bring about the conservation of valuable and diverse landscapes, especially in the Yangtze River Delta, which possesses a huge amount of rich land. 


\section{YANGTZE RIVER DELTA: WATER-SCAPE TERRITORY UNDER THE CHALLENGE}

The alluvial plain of the Yangtze River Delta is a land with a hydrological structure. Its hydraulic civilization has a long history and a fruitfully productive landscape. An ancient Chinese proverb stated that "when the crops in the regions around the Taihu Lake of Suzhou ripe, there is enough food for the people across the country." However, in the same way as other Chinese cities with an expeditious development process, after the "Great Leap Forward" - the 1958-62 economic and social campaign of rapid industrialization of China led by the Communist Party and Chairman Mao Zedong - the Yangtze River Delta has been undergoing rapid urbanization and industrialization. Simultaneously, the incompatible modern road system embedded in this urban hydrological tissue disrupted the original cultural landscape structure.

Moreover, urbanization and industrialization in the Yangtze River Delta have significantly impacted the farmland and generated severe pollution that essentially destroys environments and ecosystems (Fig. 1). For example, because of the expeditious industrialization and substandard regulation of the disposal of chemical products, more than $70 \%$ of lakes and rivers in China are contaminated, and approximately $40 \%$ of them are seriously polluted. Taihu Lake, for example, has been terribly tainted, leading to the lack of access to safe drinking water for so many people in the area (Huang, 2013). Apart from that, a 2011 analysis organized by Nanjing Agricultural University showed that $10 \%$ of rice sold in China contained immoderate amounts of cadmium, and some researchers calculated that as much as roughly $70 \%$ of Chinese farmland is adulterated with toxic chemicals (Huang, 2013).

Meanwhile, there is an increased shift from rice paddies to vegetable crop farming since water bodies and soil in the area are highly contaminated. Besides, certain crops and fishing farming have higher profits, which result in the one-sided pursuit of interests, and this is also one of reasons to make an obvious adjustment of the structure of rural production in this region. Thus, there has been a shift from rice, fish and mulberry cultivation to a large number of mega-fishponds and intensive greenhouses.

Consequently, water pollution is a major issue in the area not only because of current industrial practice and domestic water dumping into water bodies, but also intensive agriculture. Farmers have been overloading soil with nutrients, causing excess organic and chemical waste from fish and rice/vegetable farming that find their way into water sources (Fig. 2). Moreover, climate change will increase flood risks and further aggravate the water pollution problem. The erosion and water waste caused by intensive agriculture, as well as water, land and air pollution caused by industrialization and urbanization (Fig. 3), has been making the area confront serious problems, including food safety (Chen, 2007). The vicious 


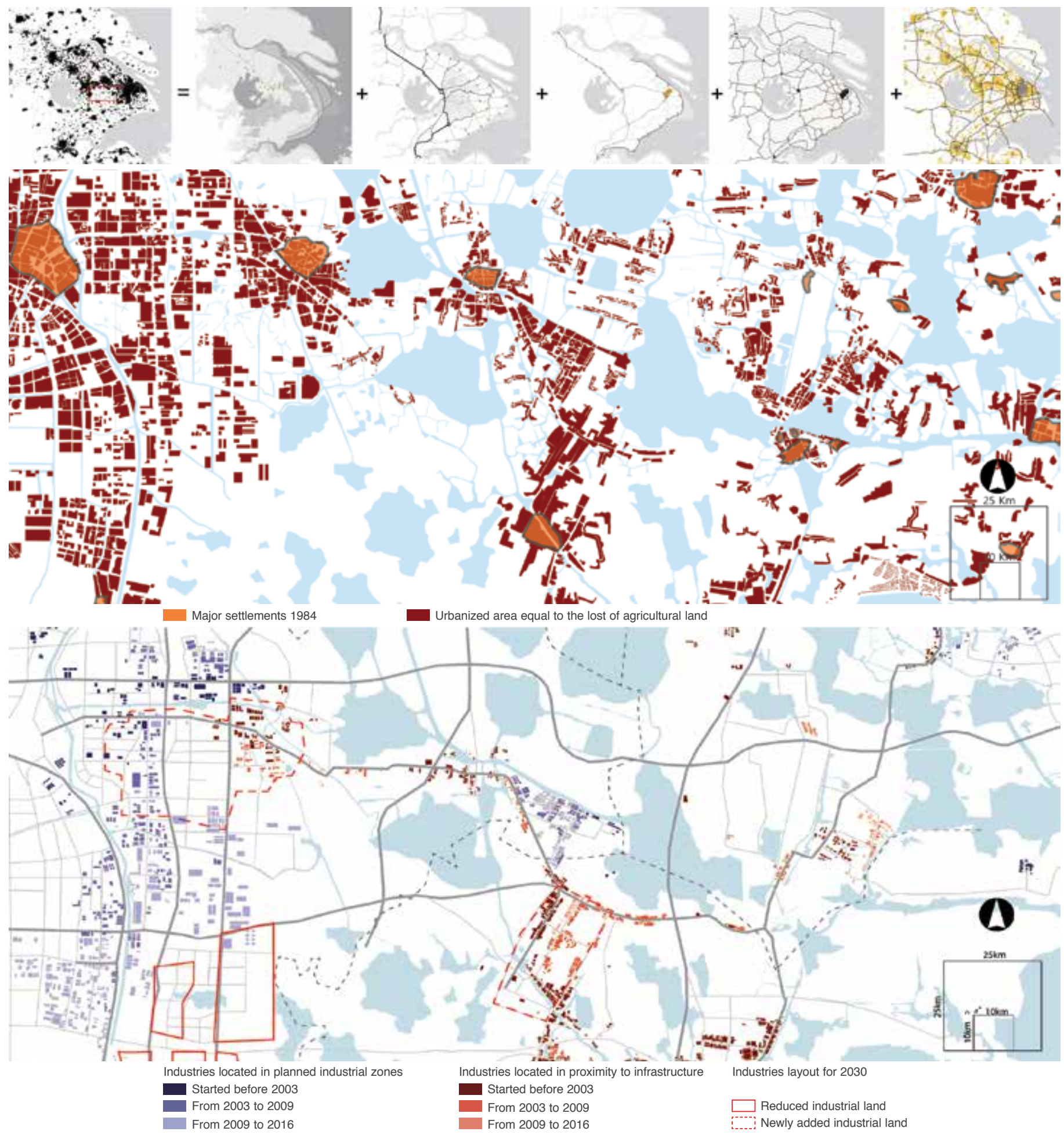

Figure 1. TOP: transformation of the Yangtze River Delta (Occupation = early settlements in a moving delta (2000 BCE to $600 \mathrm{CE}$ ) + river and canal towns in a polder landscape (610 to 1850) + port of Shanghai on a consolidated coast (1850 to 1949) + rural densification in a productive delta (1949 to 1978) + towards a metropolis in an engineered delta (1978 to 2014).

CENTER: urbanization of the corridor. The YRD area has been facing a drastic agricultural land reduction due to a rapid urbanization and industrialization.

BOTTOM: industrialization of the corridor. Industrial building in the corridor are divided into two types, industries evolving in planned industrial zones and industries evolving in the landscape using the infrastructural or other local assets of the site. 
circle between agriculture and pollution forces this area, once known as the "land of plenty," to rely on imports to meet the growing demand for food.

Food and nonfood processing industries have been implemented in medium and big cities, leaving rural or production areas with numerous abandoned industrial buildings. This delocalization, together with the low-income conditions of farming, have had an important socioeconomic impact on the population. Those factors have led to the migration of rural inhabitants towards big cities looking for more lucrative opportunities. At the same time, a large inflow of migrants from poorer regions of China have taken over farming activities. Remaining rural farmers now depend on those migrants by lending their farmland and renting their rooms. This has become an additional or, in some cases, the main source of income

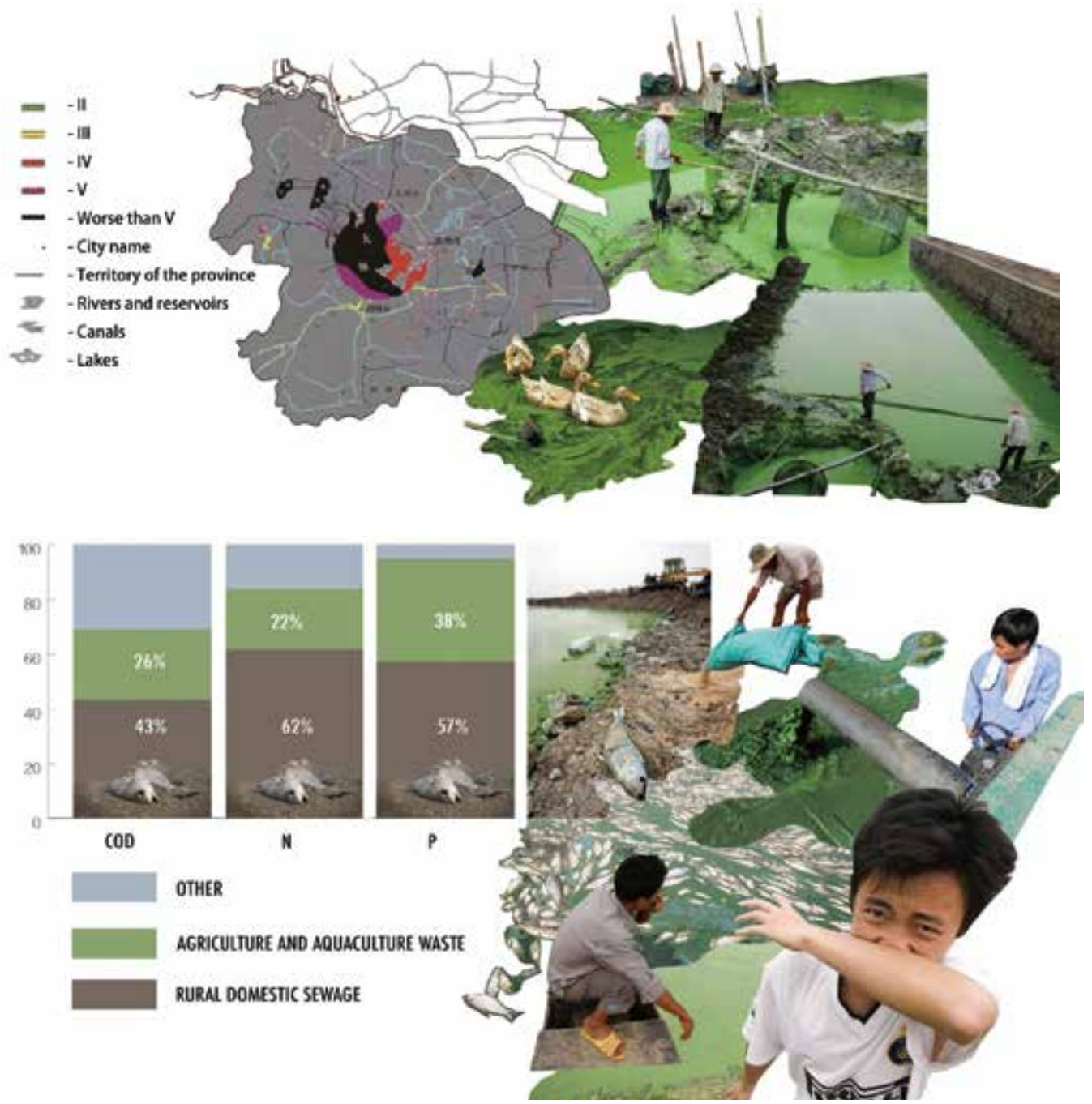

Figure 2. Top: water pollution in Taihu Basin. From green to black, which is the worse situation of the pollution. Water quality is very poor, with no water body having the purest "level I" quality (drinkable without treatment) and a large majority having a quality level above III (outside drinkable range). Bottom: influence factor of water waste. The water pollution of Taihu Lake is characterized by the severity of eutrophication and high frequency of algae bloom, which is mainly due to the domestic waste from rural and agricultural pollution. 
for remaining rural farmers. In fact, rural areas have been at the core of a profound social transformation of the local population.

Under the risk of rapid urbanization, dreadful pollution and climate change, how could the Yangtze River Delta develop? Despite such drastic transformations, one cannot ignore that the main asset of the delta is still rich land with high potentials for agriculture and aquaculture. Within this context, the main issue is how to provide a new sustainable paradigm of productive landscapes that allows not only to halt the current biodiversity crisis, but also to ensure imperative production. Moreover, how can the landscape be organized to interact with the social, economic and cultural dynamics of the region?

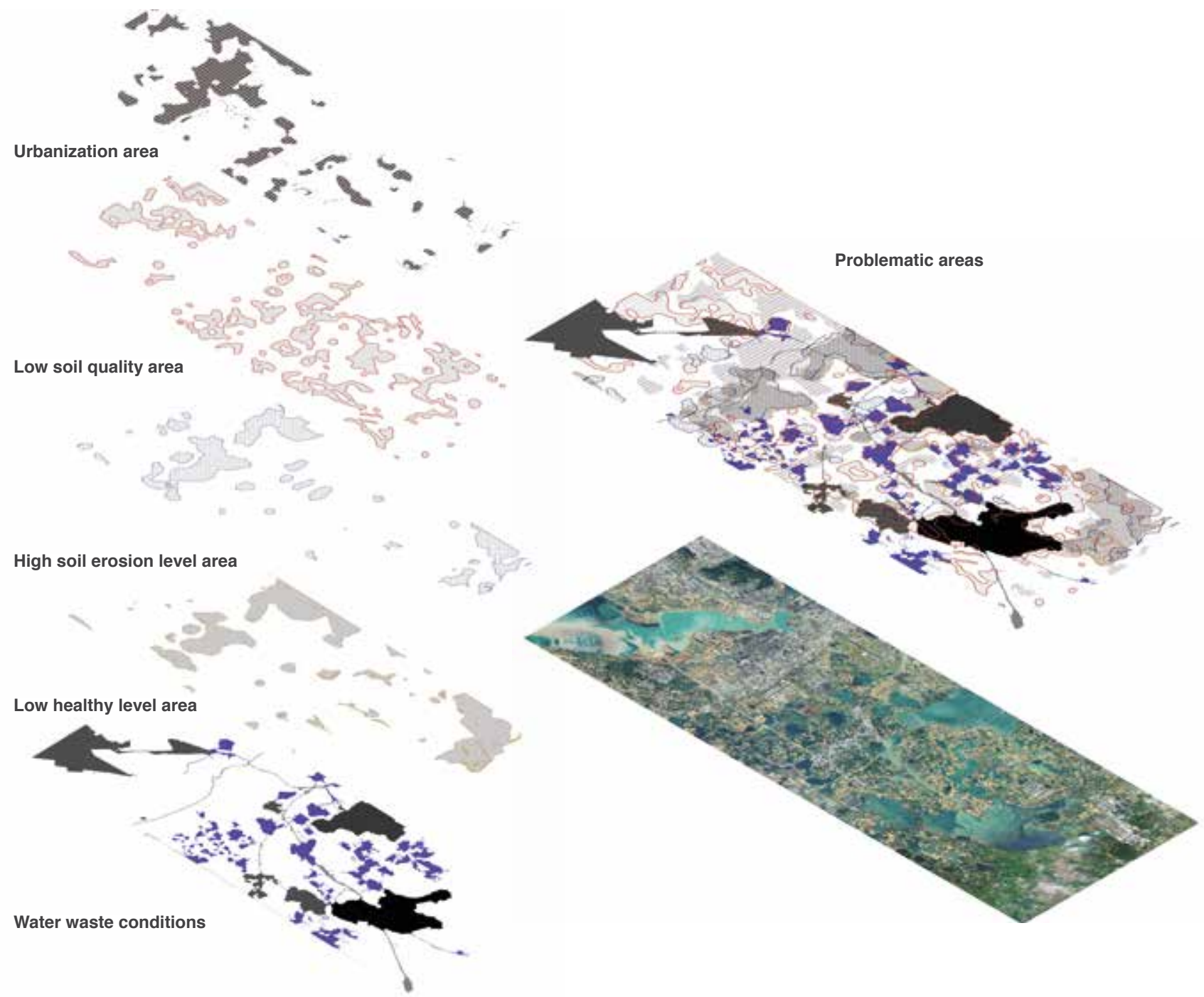

Figure 3. Soil conditions in the corridor scale (low soil quality area - assessment according to potassium, phosphorus, $\mathrm{PH}$, soil thickness and organic matter; high soil erosion level area related to low vegetation cover, less rainfall and intensive agriculture; low healthy level area caused by rapid urbanization and industrialization - assessment according to heavy chemical elements; water waste conditions). 


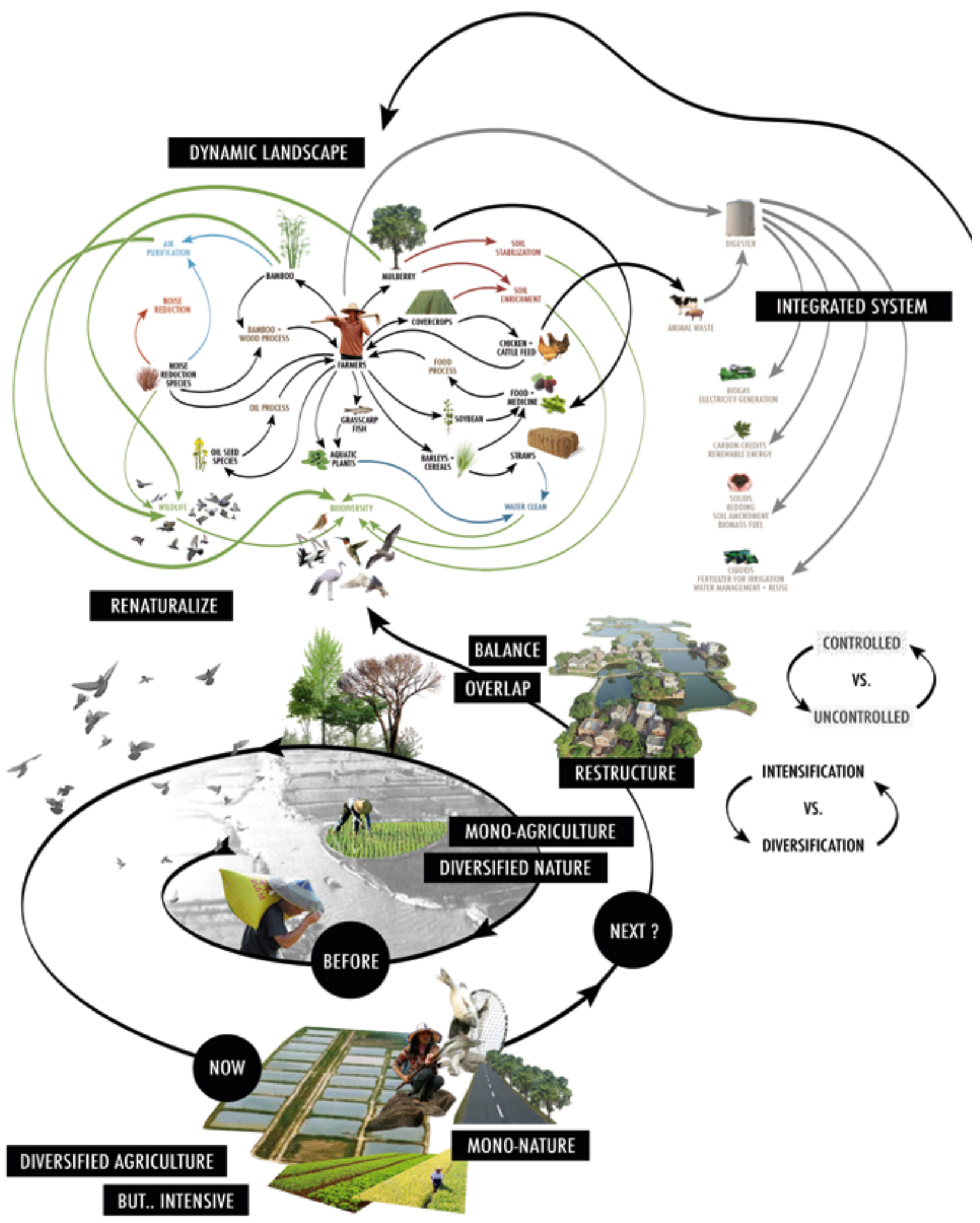

Figure 4. Concept diagram. 


\section{DESIGN STRATEGY: SHIFTING AGRICULTURE}

The design strategy (Fig. 4) is to shift the paradigm of agriculture, from mono-nature and intensive agriculture to a diversified and naturalized landscape by restoring the delta's natural properties and hydrological rhythm as well as rearranging natural dynamics including water and land. The shift to a resilient agro-economic landscape is an "eco-leap" that is definitely possible to be imagined for the future.

In order to achieve this productive landscape, local and fecund vegetal species, identified to be promoting integrated systems based on

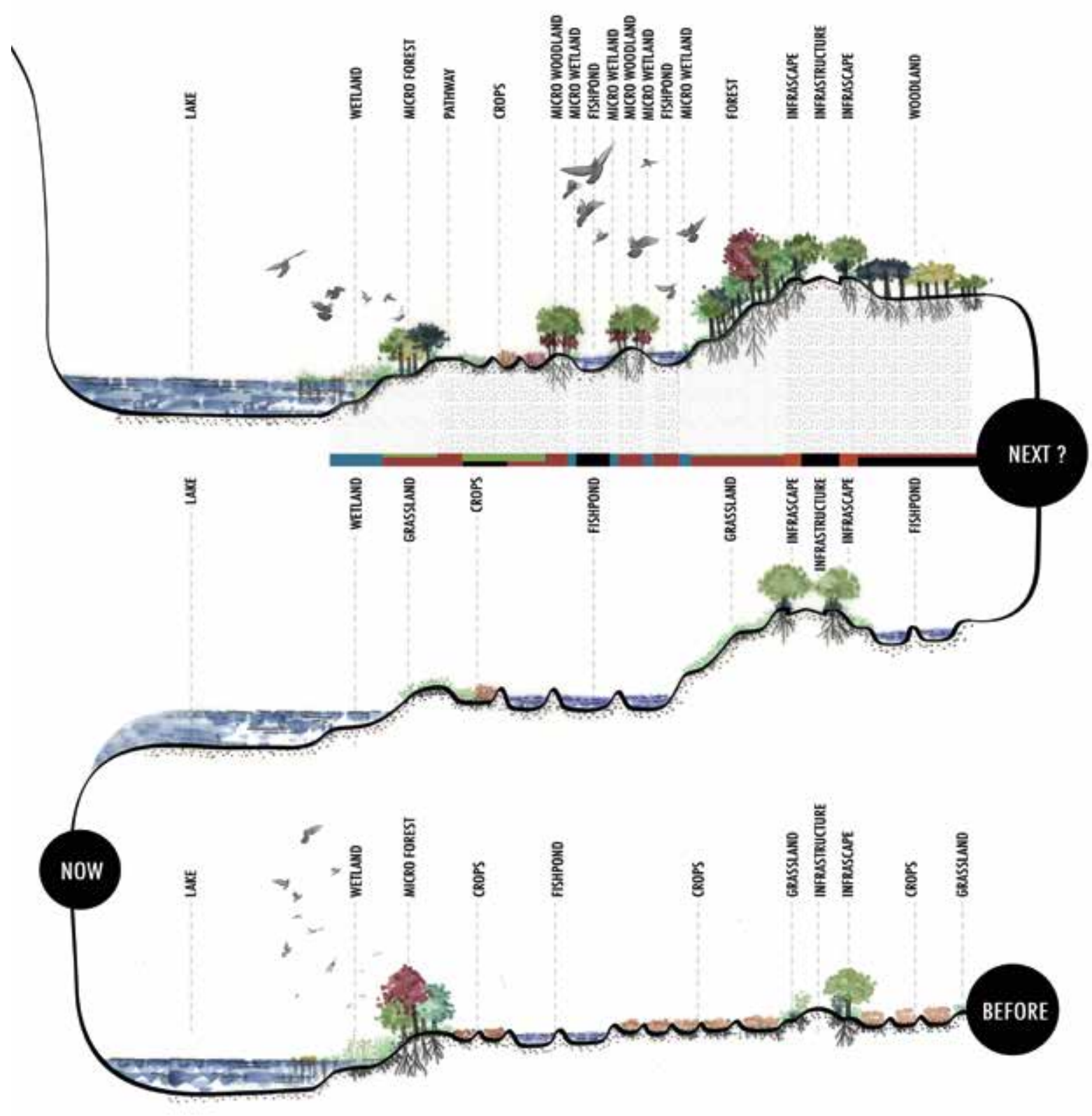


eco-systems, will be introduced, and embedded within a sustainable economic development strategy (Fig. 5). According to a research on species to be used for this design intervention, the productive species chosen to be introduced with the project are predominantly native, for example: Taxodium distichum, Castanea mollissima, or Ilex cornuta. These species could be definitely well grown in the area. In parallel, some local species, and even some protected species, which used to be planted in the region, but taken down during the process of urbanization, to be replaced by some typical types of street trees (e.g. Cinnamomum camphora), will be re-established to bring back a diverse urban environment.

Moreover, these local species could contribute to the ecosystem and economic system of the region by providing many uses and benefits. For instance, Taxodium distichum is not only an urban tree that could be cultivated as an ornamental one, but it could also be considered as a woody tree used for afforestation and prevention of soil erosion. Furthermore, the wood is widely used in buildings, ship construction, and furniture manufacture. Another example is Juniperus virginiana, which is not only cultivated for ornament and planted for afforestation, but also plays a vital role in preventing soil erosion, soil salinity, air pollution (together with bamboo); additionally, it helps attract birds and pollinating insects, including beneficial parasitic and predaceous wasps, and helps decrease the number of harmful insects for the area.

\section{"OPPORTUNITY MAP" - CONTINUOUS PRODUCTIVE LANDSCAPES}

The ecosystem needs to be understood at multiple scales - from microscopic to metro-region. At broader scales, connectivity is important because many ecosystem services depend on corridors to form networks (Ahern, 2016). In the case of the Yangtze River Delta, it is very far-sighted to coordinate the comprehensive utilization of nearby infrastructures as well as of rural agriculture, and to take advantages of any space with uncertain uses such as open spaces, old buildings and brownfields; in other words, to combine top-down and bottom-up strategies to build continuous productive landscape networks.

In terms of the bottom-up perspective, the crop planting structure has been found to be undergone tremendous changes because of the onesided pursuit of high production. There has been a huge number of mega-fishponds, while the dikes between ponds have been shrinking. The uncultivated dikes were covered with weeds, and some of them even collapsed, leading to an adverse impact on the ecological environment of fishponds.

Given both the ecological agriculture advocated by the Chinese government in recent years, and the tradition of indigenous mulberry-fishpond pattern, the DNA structure of agricultural pattern in this region should be regenerated. Besides, similar to many rapid-developing industrialized cities, also the delta saw the generation of many brownfield lands. 


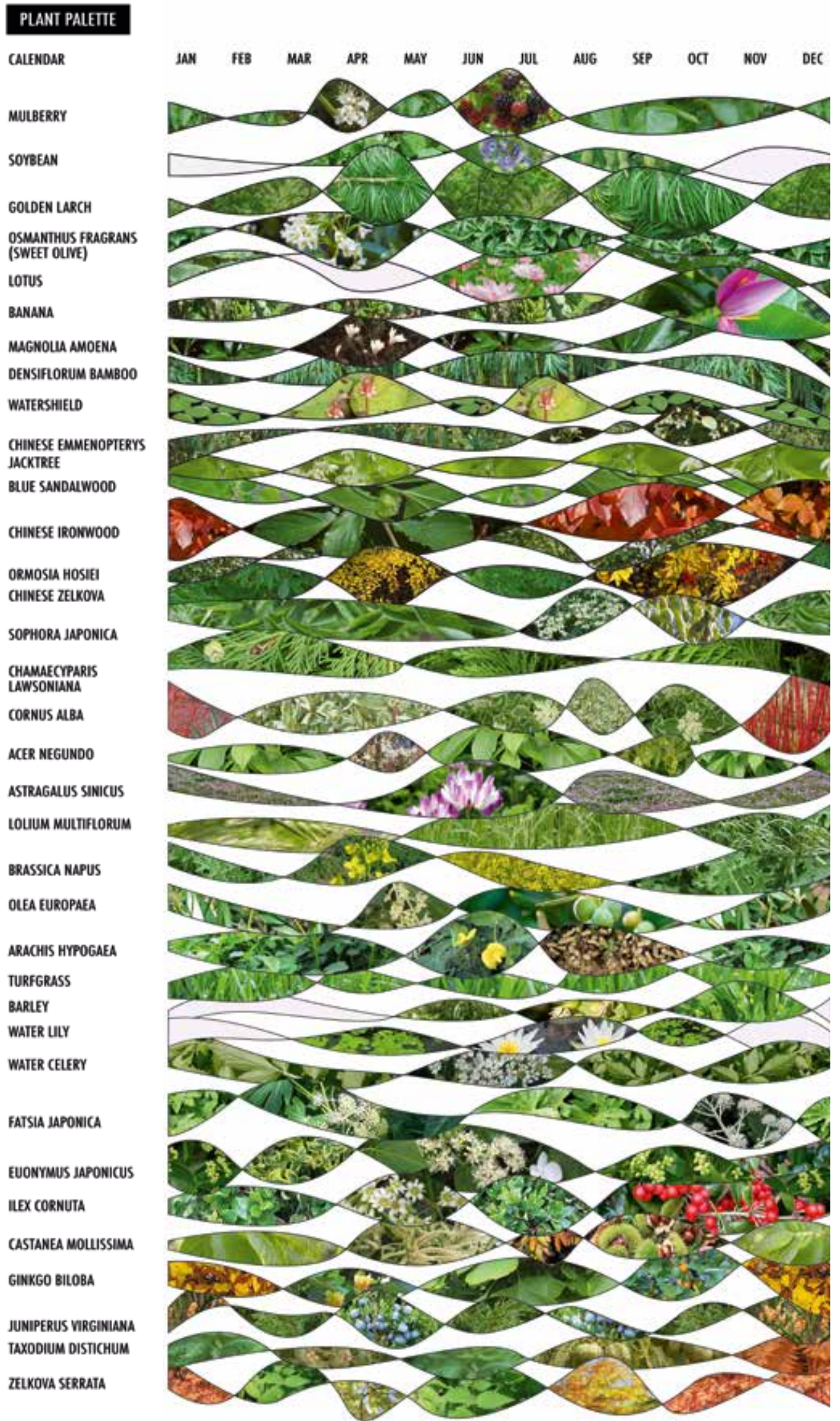

Figure 5. Plant palette. The (re)introduction of local and protected-productive species is implemented into spatial conditions according to a seasonal cycle. 
As far as the top-down perspective is concerned, taking into consideration climate change, urban-rural integration, etc., Suzhou put forward an ambitious "green corridor strategy," integrating green infrastructures with the water system, to form a blue and green network. Nevertheless, the mono-species street network, the wide underused area of the greening program and the lack of integration of different urban tissues make this excessively general plan look unconvincing. This strategy indeed provides an ideal site for multi-functional productive landscapes. (Figs. 6, 7)

\section{METHODOLOGY: MUTUAL MANAGEMENT AND CONTROL OF LAND AND WATER DYNAMICS}

It is obvious, but it needs to be emphasized, that the delta's fertile land has the potential to carry out productive landscapes, including agriculture and aquaculture, as a result of the interaction between land and water, and more precisely: topography, water depth, and soil quality (De Meulder, Shannon, and Rojas Bernal, 2015). At this time, as the delta is out of balance and order, different agro-ecological regions are separated and corresponding planting strategies are adjusted by a re-evaluation of the soil condition under the delta surface. Therefore, this strategy can balance the ecological impacts of urbanization and intensive agriculture in the region, and re-clarify the productive landscape of the delta's dynamic ecology. (Fig. 8)

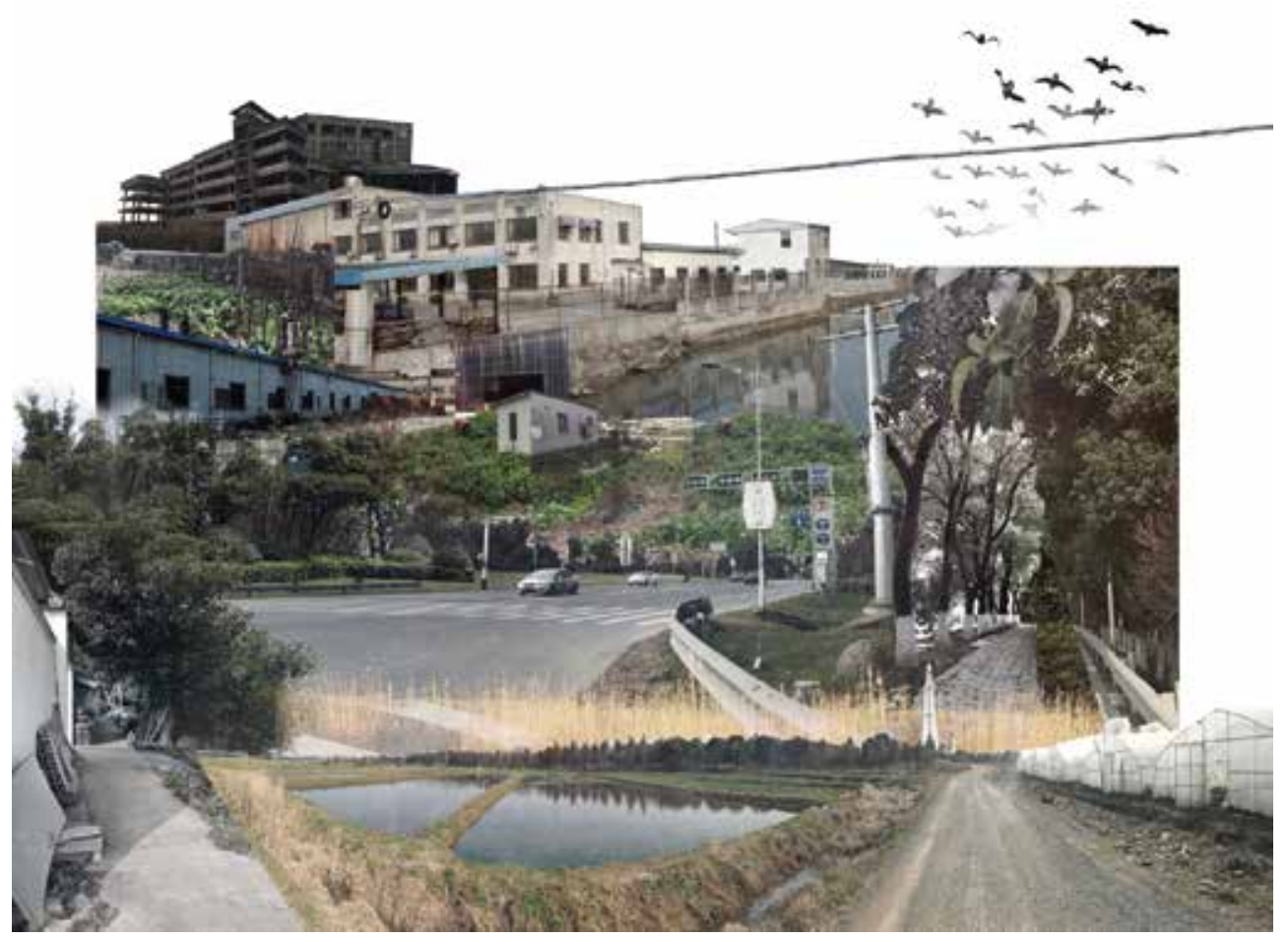

Figure 6. Collage of potential space for productive landscape. The top image represents abandoned industries, with the space for agriculture and fragmented agriculture in the village next to it; in the middle, there is an eco-infrastructure; the bottom image represents fishponds. 


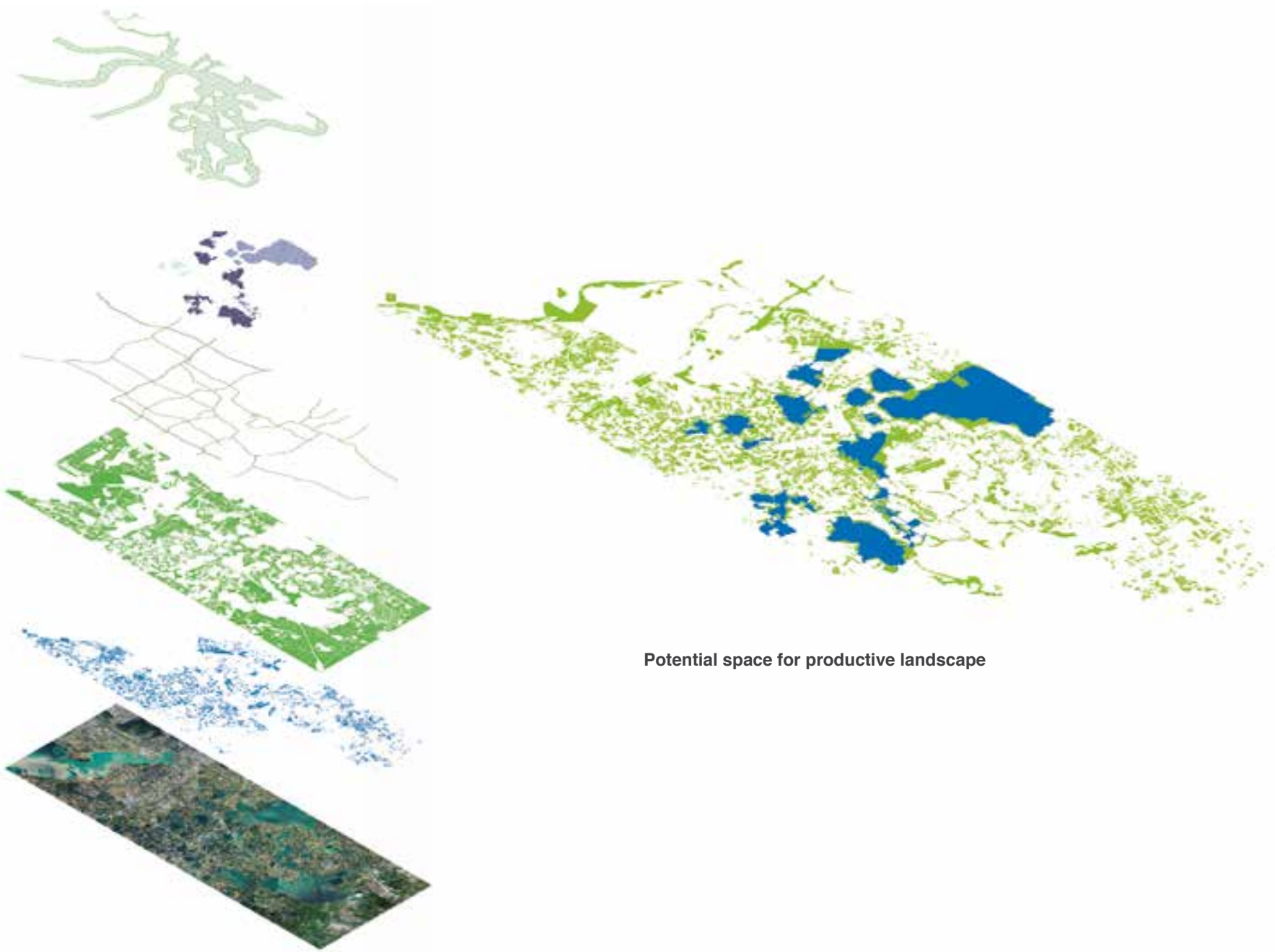

Figure 7. Potential space for productive landscape. The top-down (eco-infrastructure) and bottom-up (fishponds as DNA of agricultural units) strategies are integrated to create the productive landscape network including water, forests, and farmland.

\section{ECO-STRATEGIES IMPLEMENTATION}

The different agro-ecological zones (Fig. 9) seem to be spread all over the region, but when focusing on individual sectors, distinct spatial distribution becomes recognizable. The marked red areas, which suffered from low soil quality due to the quality of the water, are highly concentrated at the edge of water bodies. The blue areas, with high level of soil erosion, are mainly concentrated in districts of rapid urbanization and intensive greenhouses. The orange areas, with low-level healthy soil, are more concentrated in towns and villages next to industrial districts. Compared with the above, the green areas with a broad distribution have quality soil and water conditions good enough to grow diverse crops. All these zones can be sub-categorized into three types: farmland, fishpond and open green spaces. Hence, our choice, to sample within this project, of the three most representative sites in the corridor to be analyzed and implemented: "Edge of Fishponds" (fishponds in four agro-ecological zones), "Edge of Industrial Areas and Settlements" (fishponds, farmland and green spaces in orange 


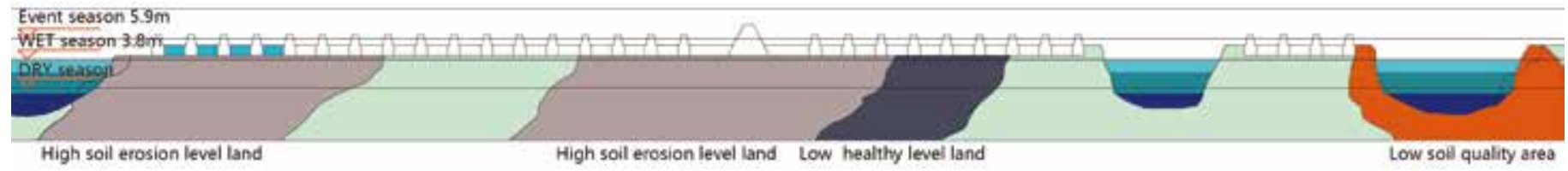

Figure 8. Section showing the situation combined with soil conditions and topography.

areas), and "Edge of Waterbodies" (open green spaces in red areas).

According to the existing agricultural ecosystem conditions, the intensive agriculture patterns on these different locations change, and multi-vegetal species identified to be promoting integrated systems are re-introduced, as embedded parts in a sustainable economic development.

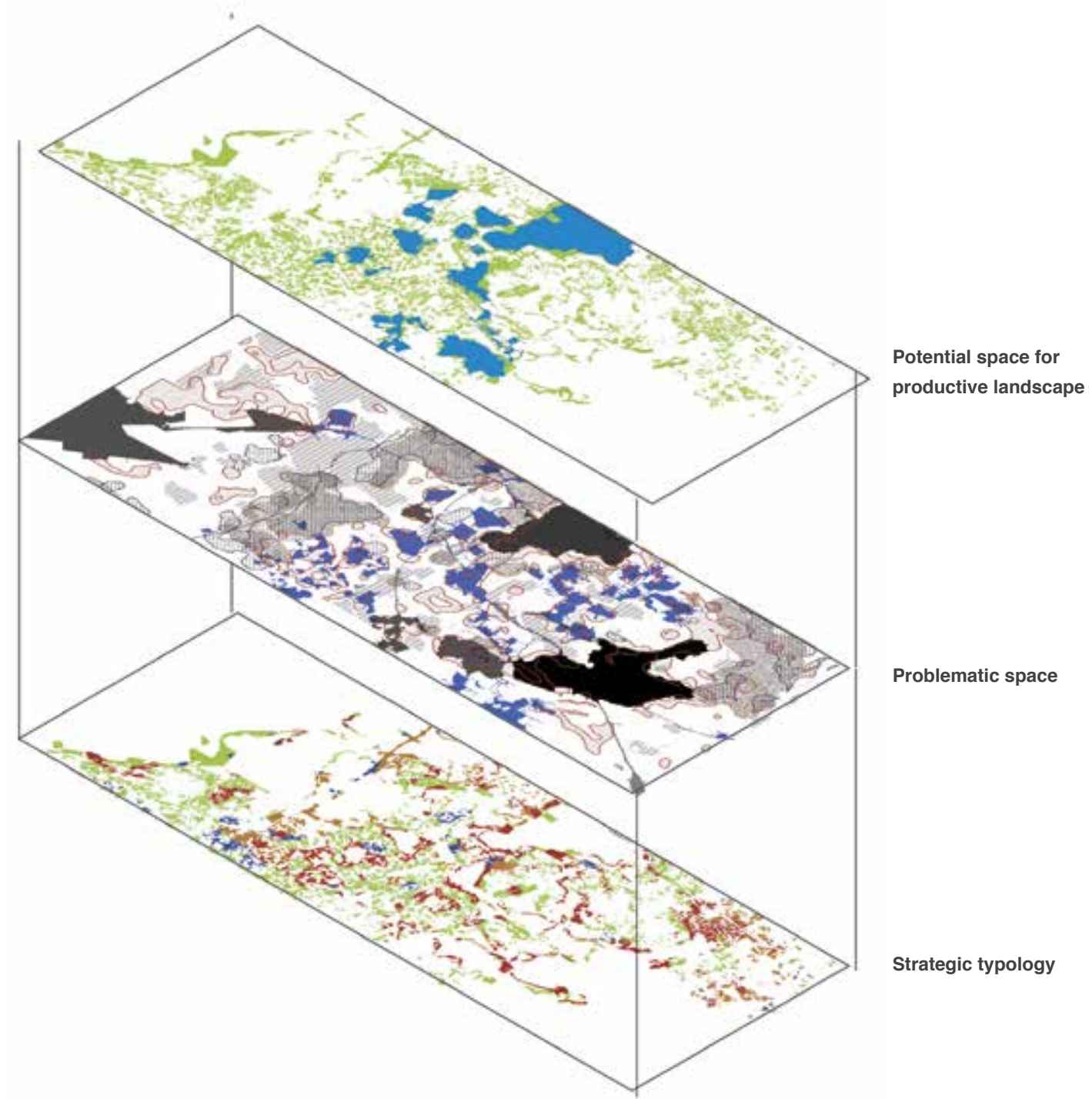

Figure 9. Different strategic typologies or agro-ecological zones are identified to implement different eco-strategies to shift agriculture by overlapping potential space for productive landscape and problematic areas defined by topography and soil conditions. 


\section{Strategy for the Edge of Fishponds}

As mentioned before, the fishpond is one of the most basic units of agriculture on site which used to be implemented in the mulberry-fish model. However, these fishponds have consolidated in the past few decades, while the dikes between ponds have been shrinking and decaying. In fact, this cultural landscape, the so-called mulberry fishpond, once found in the Yangtze River Delta, is one of the earliest examples of eco-agriculture. Based on a deep understanding of natural waterrelated characteristics and ecosystem performances, this traditional model creates a sustainable, closed system in which the waste products from one process are utilized in another (Fig. 10). Moreover, a dike-pond system is also a small artificial wetland system. By virtue of the interaction between land and water, flora and fauna, the ecological and economic benefits of pond farming are maximized. Under the contemporary challenges, this indigenous water-based productive landscape seems to provide an example to the decaying basic agricultural unit on site, intensive mega-fishpond, to become a sustainable productive landscape.

In order to balance between land and water and to create an active connection between each other, the dikes between ponds have been broadened. The dikes are high and safe, and they could help prosper functional and productive crops to co-develop. Likewise, these dikes are divided into four types, according to the specific soil conditions. Healthy

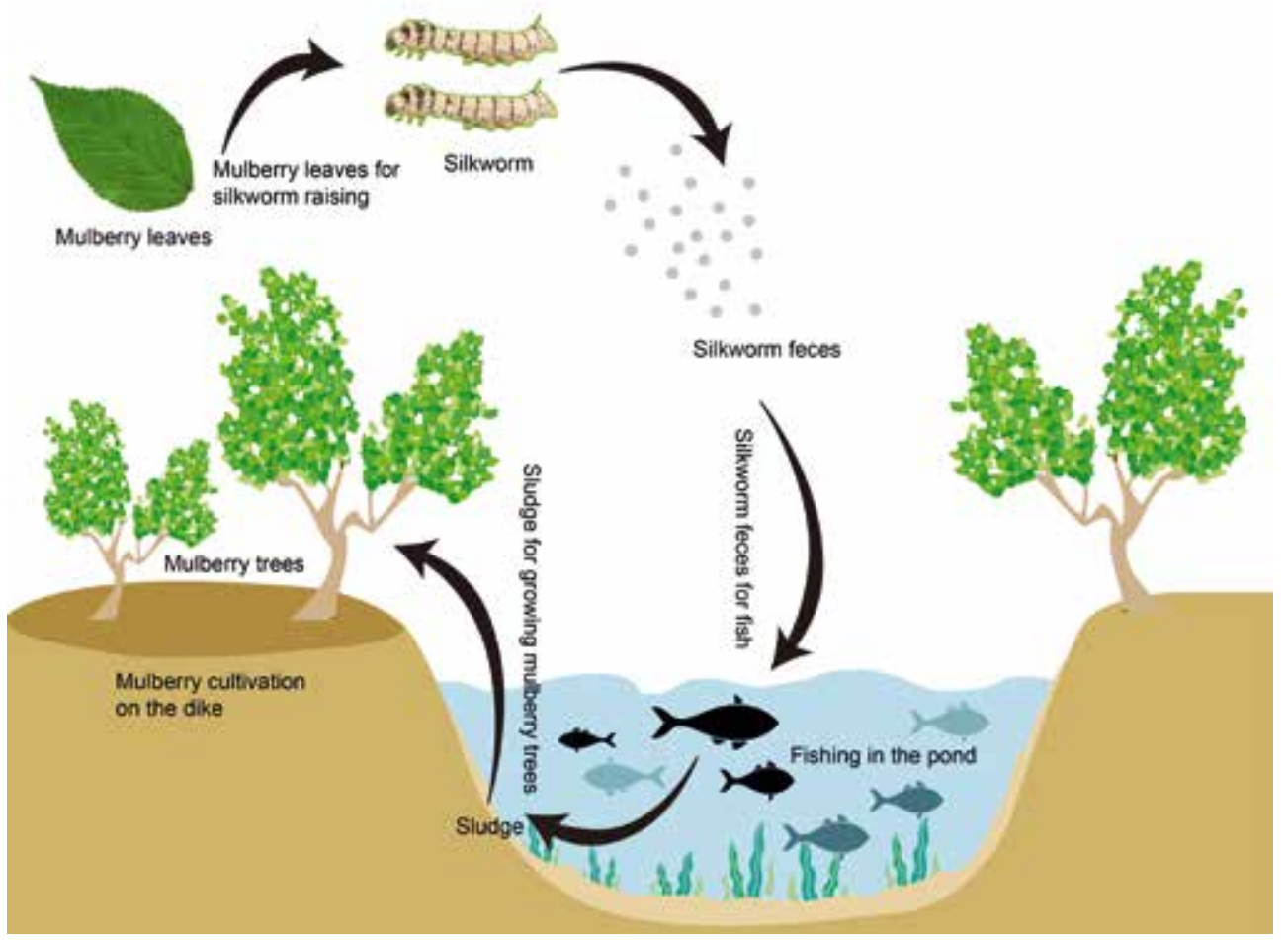

Figure 10. Traditional fishpond operation and garden plots on adjacent lands, showing energy and nutrient flows in a closed system, in which waste from one function is used in other functions. 

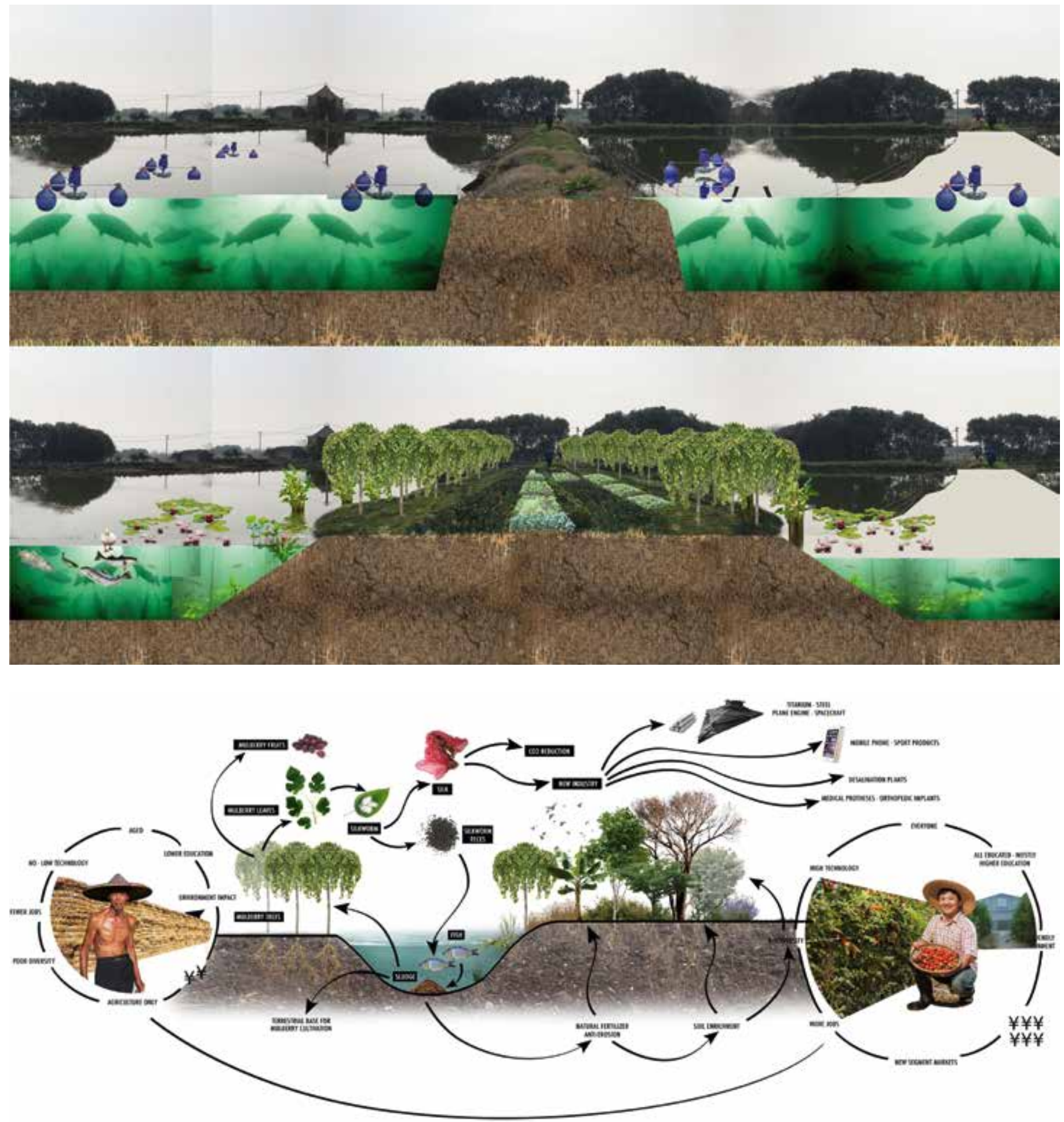

Figure 11. Strategy for fishponds with healthy soil. Top: before implementation; middle: after implementation; bottom: the mulberry cycle after implementation. The berries produced ensure food security and could be processed in the abandoned industries on the site, whereas the production of silk could be partially or totally processed in the Wujiang industrial park. Meanwhile, it can create about 15 million jobs in a decade. Moreover, as a substitute for titanium, the silk could be used by the spacecraft industry for plane engine, desalination plants, medical purposes (prostheses and orthopedic implants), sports products and mobile phones. 
and productive dikes will support the growing of mulberry trees that could enrich the soil, various crops, and fruit trees. The edge space between the dike and the pond could be seen as a micro-wetland, where local aquatic species are scattered. The interaction between ducks, aquatic plants, fishes, mulberry trees, and crops could come up with a sustainable and closed cycle. Intensive fish farming would be replaced by a self-regulating organic system that can increase lake biodiversity. The local plant mulberry - could be one of the main species to be re-introduced, because of its ecological benefits and cultural identity, as well as its new economic uses (Fig. 11).

Other types of dikes that suffered from soil pollution would have the productive and functional landscapes selected according to their soil conditions, and at the same time, they could help repair land problems. For example, dikes with low-quality soil would have the species that could enrich the soil planted; concurrently, the ponds are prone to be transformed to plant inter-cropping cereals.

\section{Strategy for the Edge of Industrial Areas and Settlements}

The land is located mainly in the transition areas between villages and industrial zones that suffer from chaotic spaces (Fig. 12). Accordingly, abundant domestic sewage pollution has threatened sensitive productive areas including mega fishponds, decaying wetlands and farmlands. Creating buffers around sensitive areas could contribute to lessening negative edge effects, a useful conceptual basis for maintaining biodiversity, ecosystem function, and ecosystem resilience in production landscapes (Fischer, Lindenmayer \& Manning, 2006).

The strategy is to cultivate the buffer zone, or micro-forest represented by bamboo and ginkgo, stitched up the crack between the industrial area and

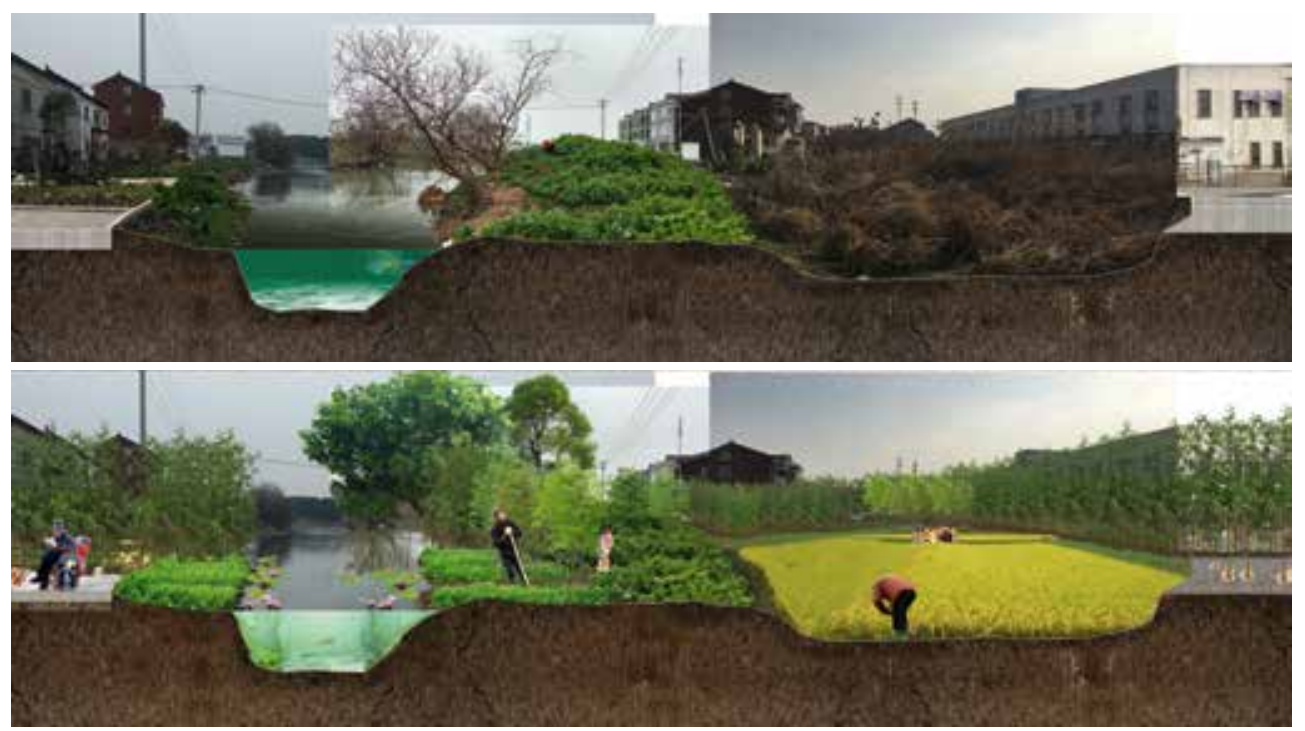

Figure 12. Strategy for brownfield. Top: before implementation; bottom: after implementation. 
the village. It would help protect and connect the fragmented farmlands and wetlands, purify the water run-off and fertilize the soil, which could make the whole eco-system more adaptive to the pressure of human industrial activities.

This strategy provides a fundamental point for the integration between conservation and production. Transforming sensitive areas and implementing buffers will play a vital role to put an end to the current biodiversity crisis. The transformation of the rich productive landscape could as well benefit the ecosystem and ameliorate living standards for people.

\section{Strategy for the Edge of Water Bodies}

The land near water bodies is mostly problematic, as lowlands suffered from soil erosion and low productivity (Fig. 13). At the same time, it is easily influenced by heavy rainfall and flooding in wet seasons. Therefore, a more natural and multifunctional adaptive system, such as the wetland, is introduced through a cut-and-fill strategy that balances the earthwork on site.

The strategy creates a flood resilient zone that develops multilayered productive landscape. The topography will be reshaped to create a slope that could create diverse productive species and wildlife habitats. The local species re-introduced to the wetlands need very little maintenance. For instance, reed is one of the local aquatic species that can clean the water and provide better living conditions for other species - various types of

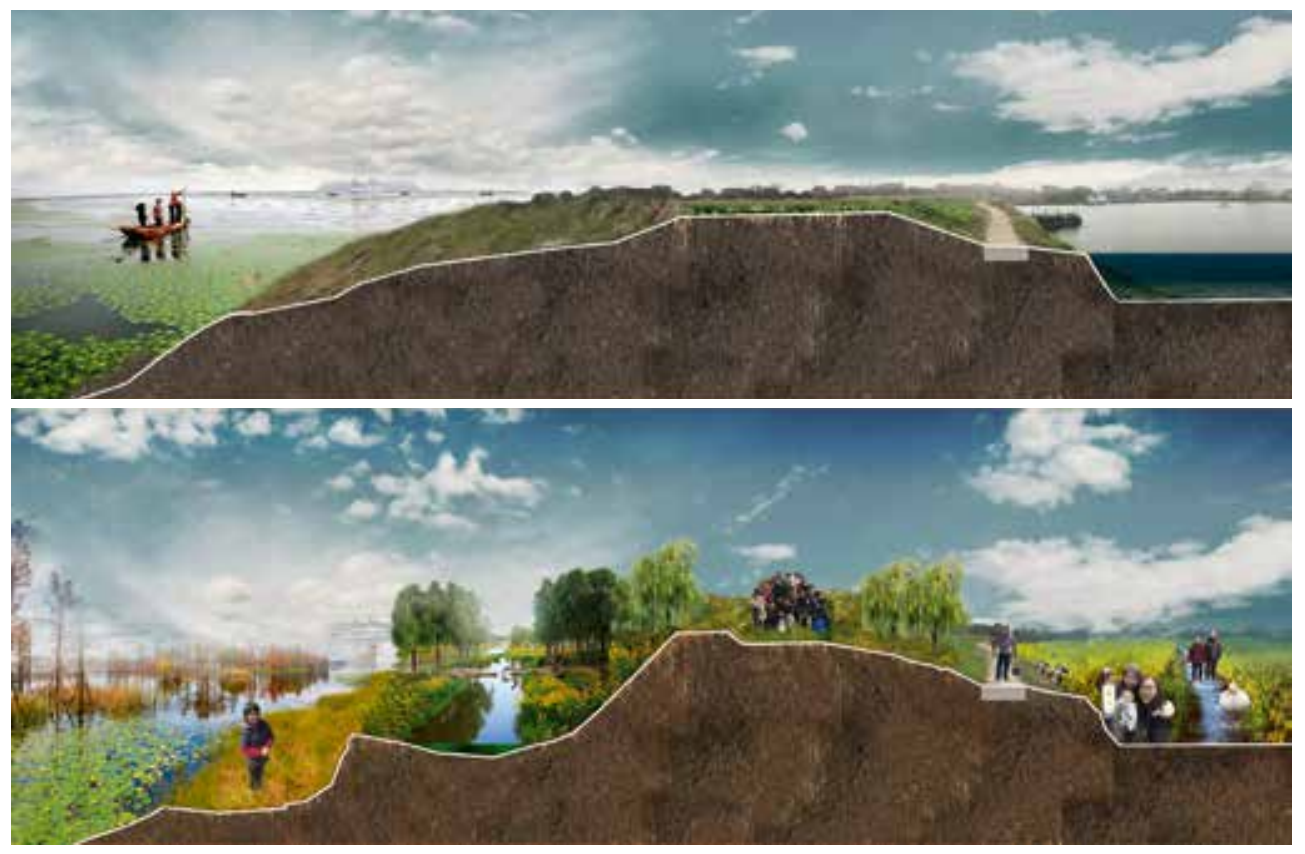

Figure 13. Strategy for the land near water bodies, as well as for fishponds with low soil quality. A micro-eco-system: Taihu Lake + Wetland + Micro forest + Farmland. Top: before implementation; bottom: after implementation. 


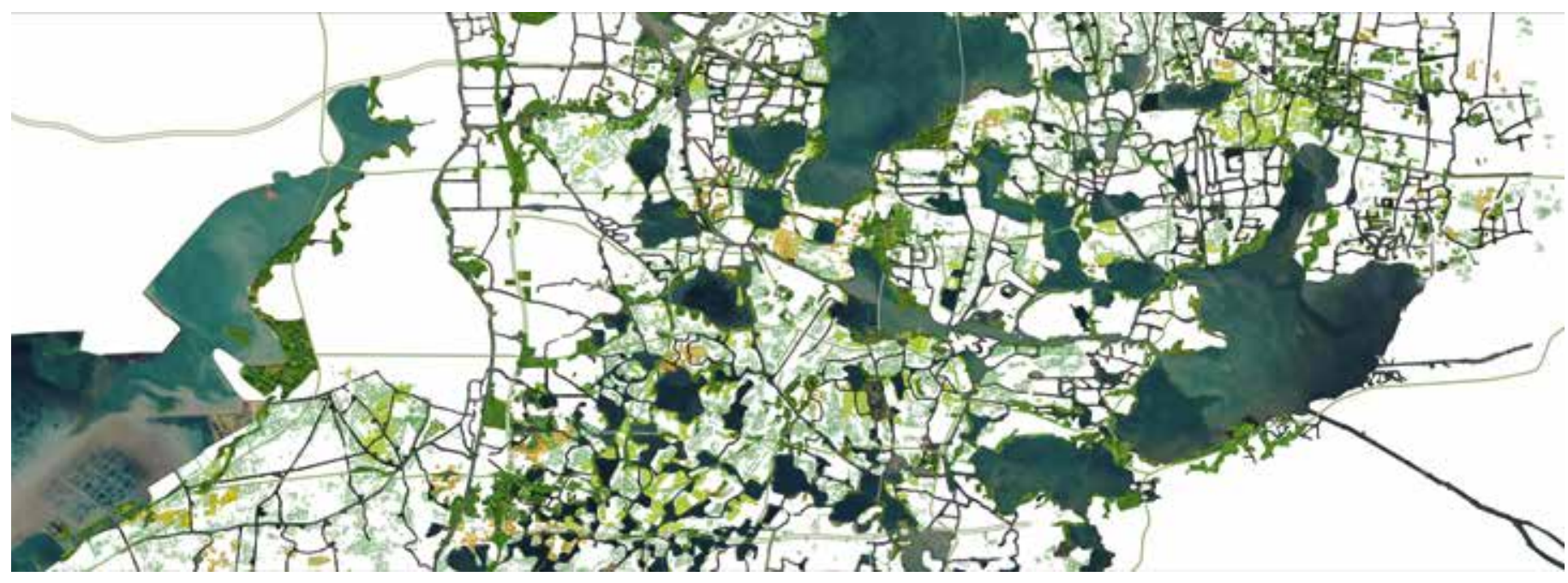

Figure 14. Strategy plan.

fish could in fact be attracted to the area again. Besides, it could also be harvested as a Chinese medicinal herb and used in everyday life as pillow and broom. Additionally, within the constructed wetlands, micro-topographic alteration generates flexible spaces that are not only productive of local species for high-valued industries, but that could also allow people to enjoy the multi-layered landscape adaptive to the seasonal floods, and protect the farmlands behind it.

In the whole delta region, the micro-eco-systems and nature will be merged and susceptible to work together across scales. (Fig. 14)

\section{Interaction and Co-Benefits: Industrial Platform, Land and Water Transportation}

There are two principal benefits from these eco-strategies. Firstly, the ecoagricultural system increases the resilience of the agriculture as well as the industry. The transformation of the planting structure including mulberry, peanuts, bamboo, ginkgo, etc. could build a more diversified industrial economy. Besides mulberry, Arachis hypogaea or peanuts, for example, in addition to being used for food, is used as a source of oil, soap, cosmetics, green fertilizer, fodder, and paper. Therefore, there will be a big demand for processing industry once Arachis hypogaea is introduced to be cultivated widely in the area. Another example is the ginkgo biloba, whose wood is used in furniture making, the leaves are medicinal and used for pesticides, the roots are used as a cure for leucorrhea and the seeds are edible. Hence, ginkgo biloba will also generate a new era of processing industry for the whole region of the Yangtze River Delta. These productions could meet the needs of everyday life and simultaneously provide a high potential to extend the production and processing chain to build high-end products by collaborating with cultural entrepreneurship and research institutes (Fig. 15). 
Meanwhile, this strategy would create a relationship between the productive landscape and the drosscape, leading the development of the agroindustry. As it can be seen from Figure 1, there are two types of industries, and the second one concerns old traditional industries that are in the process of being transformed. Besides, a revised plan about moving some industrial areas out of the corridor has been proposed by the city of Wujiang, with the aim to conserve the water landscape.

On one hand, the present industries could become brownfield after the removal, leading to the creation of new open land to organize the productive landscape according to soil conditions - although the soil of sites once occupied by factories should be examined - and giving the new appearance to these former industrial areas. On the other hand, given the lack of food-processing system within the corridor, these empty and abandon factories will be transformed into high-valued production industries to store and process agricultural products.

Thanks to high accessibility along the infrastructure, more complex space combined with institutes, public space, and recreational services, can be created. Thereby, this combination could not only meet the demand of local people but also attract all aspects of "talent" such as highly-educated farmers, outgoing farmers, researchers, and young people to achieve sustainable development.

The strategy will blend with the surrounding area on both local and regional scale not just by continuous productive landscape but also by social and economic activities to reach a holistic urban-rural continuum without boundaries between urban, rural and industrial areas.

Secondly, the region with a dense water network does not have a systematic land transportation, even if the government keeps building new roads. Moreover, the desolate water transportation makes remote villages inaccessible. The development of agriculture and industry could become an opportunity to revive the waterways, which are much cheaper and more environmentally friendly, reaching the balance between land and water transportation. It provides excellent opportunities to form a multi-level ecological and efficient public transport system, as well as strengthen the exchange of the flow of goods, people, and information.

\section{BACK TO THE FUTURE}

Traditionally, the production and life of people living in the Yangtze River Delta depend on the hydrological structure. Engineering, modernization, and strong economics-driven policies have significantly changed the relationship between life and water. Climate change and acute pollution force people to rethink this area, which could be clearly seen as a rich low-lying alluvial plain with dense water networks. Returning back to the past, back to the delta's indigenous civilization, also means moving forward into the future.

The major strategy is to revive diverse productive landscape to support 


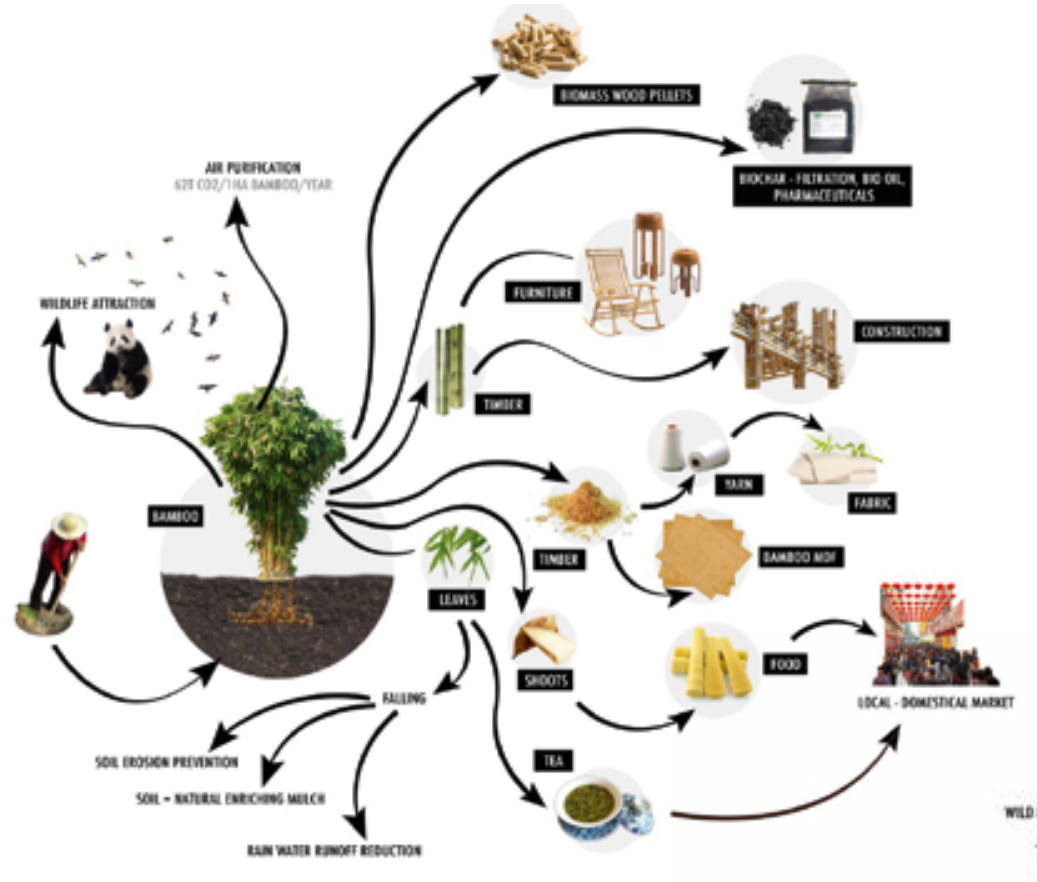

Figure 15. From top to bottom, the bamboo cycle, the peanuts cycle, the ginkgo cycle.
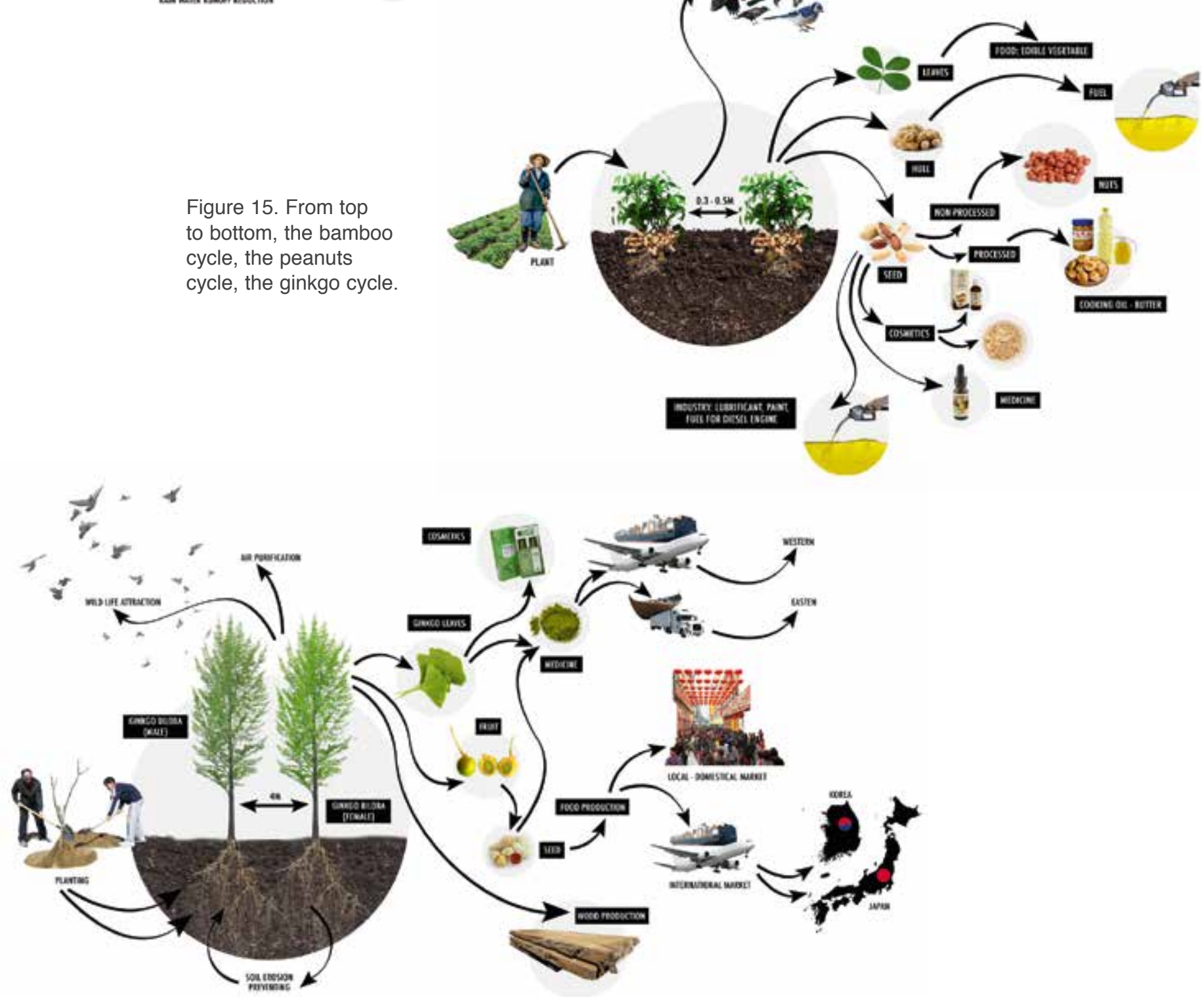
urban sustainability and resilience by creating the optimal interaction between water and land in spite of contemporary environmental pressure. Meanwhile, the interventions on the landscape dynamics are applied across scales, interacting with economic, social, and cultural aspects. Finally, these continuous productive landscapes, integrated with brownfield, eco-infrastructure and farmland, will also interweave with nature.

\section{References}

Ahern, Jack F. "Novel Urban Ecosystems: Concepts, Definitions and a Strategy to Support Urban Sustainability and Resilience." Landscape Architecture Frontiers 4, no. 1 (2016): 10-22.

Chen, Cheng, and Chen Lin. "Cultivated Land Quality Assessment and Protection Zoning in Southern Jiansu." Resources and Environment in the Yangtze Basin 25, no. 12 (2016): 1860-1869.

Chen, Jie. "Rapid Urbanization in China: a Real Challenge to Soil Protection and Food Security." Catena 69, no. 1 (2007): 1-15.

Daher, Racha, Stefanie Dens, and Bruno De Meulder. "Reviving Territories of Hydraulic Civilization." Issuu. Last updated June 25, 2017. https://issuu.com/rachadaher/docs/ reviving_territories_of_hydraulic_c.

De Meulder, Bruno, Kelly Shannon, and Claudia Lucia Rojas Bernal. "A Vietnamese Mekong Delta Regional Plan 2030 and Vision to 2050: Accentuating Six Agro-Ecological Regions." Nanfang Jianzhu/South Architecture 3 (2015): 41-47.

Fischer, Joern, David B. Lindenmayer, and Adrian D. Manning. "Biodiversity, Ecosystem Function, and Resilience: Ten Guiding Principles for Commodity Production Landscapes." Frontiers in Ecology and the Environment 4, no. 2 (2006): 80-86.

Huang, Yanzhong. "China: The Dark Side of Growth." YaleGlobal Online. June 6, 2013. https://yaleglobal.yale.edu/content/china-dark-side-growth.

Institute of Public \& Environmental Affairs (IPE), 2017. http://wwwen.ipe.org.cn/index.aspx.

Ji, Xiaohui. "Status Quo of Agricultural Landscape and Renewal Strategy Analysis of Huzhou City's 'Mulberry-Base Fishponds'." Development of Small Cities \& Towns 3 (2009): 91-93.

Liu, Tong, and Xiang-rong Wang. "Focusing on Agricultural Landscape: Study on the Regional Landscape of River Network Plain in Taihu Basin." Landscape Architecture 8 (2015): 23-28.

Mori, Akira S. "Resilience in the Studies of Biodiversity-Ecosystem Functioning." Trends in Ecology \& Evolution 31, no. 2 (2016): 87-89.

Wang, Y., and Sun, J. "Study on the Application of Circular Economy in the Project of 'Mulberry Fish Pond' in New Countryside." Project Management Technology 1 (2009): 282-285.

Wu, T., and Wu, D. "Study on the Vernacular Landscape in the Perspective of Landscape Architecture - Taking the River Network Plain in Taihu Basin as an Example." Chinese Landscape Architecture 12 (2014): 40-43.

Yuan, Xingzhong, Chunlan Du, and Jia Yuan. "Multi-Functional Dike-Pond System Adaptive to Water Level Change: Application of Pond-Based Ecological Wisdom in Ecological Restoration of the Hydro-Fluctuation Belt of the Three Gorges Reservoir." Landscape Architecture Frontiers 1 (2017): 8-21.

\section{Acknowledgments}

We would like to take this opportunity to express our wholehearted gratitude to our supervisor, Prof. Bruno De Meulder, from the Faculty of Engineering Science of Katholieke Universiteit Leuven, and our assistant supervisor, Ms. Racha Daher. Their admirable guidance, insightful criticism, valuable feedbacks, and persistent encouragement, throughout the duration of the project, allowed us to finalize this research at its best. 


\section{Credits}

Figure 1: image credits to Christian Nolf (top), and Reviving Territories of Hydraulic Civilization (bottom).

Figure 2: public domain, http://wwwen.ipe.org.cn/index.aspx.

Figure 3: image credits to Cheng Chen and Chen Lin.

Figures 4, 6-9, 11-15: images provided by the Author.

Figure 5: image provided by the Author.

Figure 10: public domain: http://hometexjoin.com/.

Xinyu Xiao conducts research in the European Post-Master in Urbanism (EMU) at the Catholic University of Leuven (KU Leuven) in Leuven, Belgium, and Delft University of Technology (TU Delft) in Delft, Netherlands. She holds a BArch from the South China University of Technology (SCUT) in Guangdong, China. E-mail: xiao.xinyu0615@gmail.com

Hai Anh Nguyen holds an Advanced Master's degree in Human Settlements (MaHS) from the Catholic University of Leuven (KU Leuven) in Leuven, Belgium. She received her BArch from the Hanoi Architectural University (HAU) in Hanoi, Vietnam.

E-mail: haianhng hau@gmail.com 